\title{
Polymorphism of carbon oxidation of drugs and clinical implications
}

\author{
T P SLOAN, A MAHGOUB, R LANCASTER, J R IDLE, R L SMITH
}

British Medical fournal, 1978, 2, 655-657

\section{Summary and conclusions}

Eight volunteers previously phenotyped for their ability to hydroxylate debrisoquine (four extensive metabolisers (EM), four poor metabolisers (PM)) were investigated for their metabolic handling of guanoxan and phenacetin. All three drugs are oxidised at carbon centres. Oxidative dealkylation of phenacetin was determined by measuring the rate of formation of paracetamol.

The EM subjects excreted mostly metabolites of guanoxan (mean $29 \%$ of dose), whereas the PM group excreted large amounts of unchanged drug ( $48 \%$ of dose). The rate of formation of paracetamol was noticeably slower in the PM group, and, when analysed by minimum estimates of apparent first-order rate constants, the difference between the two phenotypes was significant. Thus the hydroxylation defect shown for debrisoquine metabolism carries over to the oxidative metabolism of phenacetin and guanoxan.

Some $5 \%$ of the population are genetically defective hydroxylators of drugs. Thus methods for evaluating the metabolism of new drugs in respect of usage and side effects need to be revised.

\section{Introduction}

Drug metabolism is a major determinant of the therapeutic and toxic responses to many drugs. Metabolism of a drug, however, may be highly variable, and this is often the source of major interpatient variations in response to drugs. A person's metabolic capacity depends on the interaction of various genetic, environmental, physiological, and possibly pathological factors. Some drug metabolism reactions are mainly under genetic control and exhibit polymorphism in the population. Examples are the polymorphic acetylation of various amino compounds such as sulphonamides and hydrazines. The therapeutic implications of polymorphic acetylation of drugs have been discussed. ${ }^{2}$ The hydrolysis of certain ester drugs such as succinylcholine (suxamethonium) and paroxon is also mainly under genetic control and exhibits polymorphism. ${ }^{34}$

The most common metabolic reaction in the metabolism of drugs is oxidation at a carbon centre: this may be aliphatic, alicyclic, or aromatic. Despite the prevalence of carbon oxidation in drug metabolism no examples of polymorphism of such reactions have been described, though several have a genetic component, which in some cases has been quantified. ${ }^{56} \mathrm{We}$

Department of Biochemical and Experimental Pharmacology, St Mary's Hospital Medical School, London W2 1PB

T P SLOAN, BSC, postgraduate student

A MAHGOUB, MB, CHB, postgraduate student (now lecturer in clinical pharmacology, University of Alexandria)

R LANCASTER, MRCP, PHD, consultant and honorary senior lecturer in clinical pharmacology

J R IDLE, BSC, PHD, lecturer in biochemical pharmacology

R L SMITH, PHD, DSC, professor of biochemical pharmacology

have reported the occurrence in Caucasians of a polymorphism in respect of the carbon oxidation of the antihypertensive drug debrisoquine. ${ }^{7}$ Some people (about $5 \%$ of the population) have a reduced ability to effect the alicyclic hydroxylation of this drug and, furthermore, are more sensitive to its hypotensive effects. ${ }^{8}$ Apparently this 4-hydroxylation of debrisoquine is under the control of the alleles at a single autosomal locus and defective alicyclic hydroxylation is a recessive character.?

Because of the importance of carbon oxidation as a determinant of drug response it became necessary to know whether the alleles responsible for the polymorphic metabolism of debrisoquine also control the oxidation of other drugs. We therefore examined the oxidative metabolism of two model substratesnamely, phenacetin and guanoxan-in subjects previously phenotyped for their ability to hydroxylate debrisoquine. Phenacetin, guanoxan, and debrisoquine each undergo three different types of carbon oxidation-namely, oxidative dealkylation, aromatic hydroxylation, and alicyclic hydroxylation.

\section{Investigation and results}

GUANOXAN

Guanoxan (2-guanidinomethyl-1, 4-benzodioxan) is an antihypertensive drug chemically and pharmacologically related to debrisoquine and guanethidine. Jack et al showed that it undergoes oxidative metabolism to give phenolic metabolites. ${ }^{9}$ Their study included a woman who excreted only the unchanged drug with no evidence of phenolic metabolite formation. Apparently she was not further investigated.

We studied the metabolism and elimination of guanoxan in a panel of eight volunteers, four of whom were phenotyped as extensive metabolisers (EM) and four as poor metabolisers (PM) in respect of debrisoquine 4-hydroxylation. Each received a single tablet of Envacar containing $10 \mathrm{mg}$ guanoxan sulphate. Urine samples were collected hourly for up to eight hours after administration. These samples were then analysed for guanoxan and its phenolic metabolites by gas chromatography using a modification of an assay for guanidine drugs. ${ }^{10}$

Table I shows the pattern of urinary elimination of guanoxan by the eight volunteers. The metabolic ratio was calculated as: $\%$ dose

TABLE I-Hydroxylation of guanoxan and phenotypes of eight volunteers

\begin{tabular}{|c|c|c|c|c|c|}
\hline \multirow{2}{*}{ Subject } & \multirow{2}{*}{ Sex } & \multirow{2}{*}{$\begin{array}{l}\text { Hydroxylation } \\
\text { phenotype* }\end{array}$} & \multicolumn{2}{|c|}{$\begin{array}{l}\text { Characteristic and \% of dose } \\
\text { excreted in urine in } 8 \text { hours }\end{array}$} & \multirow{2}{*}{$\begin{array}{c}\text { Metabolic } \\
\text { ratio }\end{array}$} \\
\hline & & & Unchanged & $\begin{array}{c}\text { Hydroxylated } \\
\text { metabolites } \dagger\end{array}$ & \\
\hline $\begin{array}{l}1 \\
2 \\
3 \\
4 \\
5 \\
6 \\
7 \\
8\end{array}$ & $\begin{array}{l}M \\
M \\
M \\
F \\
M \\
M \\
M \\
M\end{array}$ & $\begin{array}{l}\text { PM } \\
\text { PM } \\
\text { PM } \\
\text { PM } \\
\text { EM } \\
\text { EM } \\
\text { EM } \\
\text { EM }\end{array}$ & $\begin{array}{r}31 \cdot 0 \\
48 \cdot 0 \\
60.0 \\
53 \cdot 0 \\
1.3 \\
1.9 \\
1 \cdot 2 \\
1.5\end{array}$ & $\begin{array}{r}4 \cdot 2 \\
6 \cdot 2 \\
7 \cdot 6 \\
6 \cdot 7 \\
36 \cdot 0 \\
25 \cdot 0 \\
26 \cdot 0 \\
29.0\end{array}$ & $\begin{array}{l}7.4 \\
7.7 \\
7.9 \\
7.9 \\
0.04 \\
0.08 \\
0.05 \\
0.05\end{array}$ \\
\hline
\end{tabular}
*Determined by metabolic ratio for 4-hydroxylation of debrisoquine. ${ }^{7} \mathrm{PM}=$ Poor
metabolisers. EM $\mathrm{Ex}$ Extensive metabolisers.

†Consisted of about equal amounts of 6- and 7-hydroxyguanoxan.

excreted as unchanged guanoxan $/ \%$ dose excreted as hydroxylated metabolites. There was a pronounced difference between the tvjo phenotypes in the metabolic disposition of guanoxan. The four EM subjects excreted the drug mostly as 6- and 7-hydroxyguanoxan (mean $29.0 \pm$ SD $5.0 \%$ of dose) with only small amounts of the unchanged drug $(1.5 \pm 3.0 \%)$. In contrast, the PM group excreted large 
amounts of the unchanged drug $(48 \cdot 0 \pm 12 \cdot 4 \%)$ with only small amounts of the metabolites $(6 \cdot 2 \pm 1 \cdot 4 \%)$. The mean metabolic ratio for the EM phenotype was $0.06 \pm 0.02$, and for the PM phenotype $7 \cdot 8 \pm 0 \cdot 2$.

The pharmacogenetics of hydroxylation of guanoxan and debrisoquine in these subjects appeared to be the same. The results also show that the aromatic hydroxylation of guanoxan is polymorphic and that there are at least two phenotypes, one of which is characterised by a reduced ability to metabolise the drug.

\section{PHENACETIN}

Phenacetin is metabolised along several pathways, the main one being oxidative de-ethylation to paracetamol, which is excreted in a conjugated form. ${ }^{11}$ The rate of oxidative dealkylation of phenacetin taken by mouth was investigated in the same panel of volunteers by measuring the rate of formation of paracetamol. This was assessed by determining the rate of elimination of paracetamol conjugates by colorimetry.

Each subject took a gelatine capsule containing $500 \mathrm{mg}$ phenacetin. Urine samples were collected hourly for eight hours, an 8-24-hour collection then being made and the samples bulked. The samples were then analysed for paracetamol by colorimetry after enzymic deconjugation. ${ }^{12}$

The figure shows the rate of formation and elimination of paracetamol in the EM and PM subjects. The rate of formation in the PM phenotype group was noticeably slower than in the EM group.

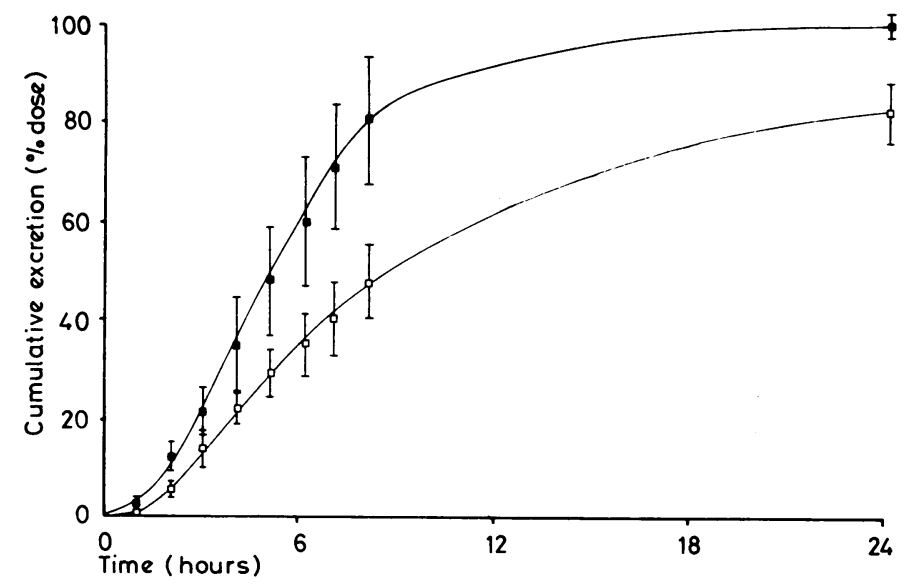

Cumulative urinary excretion of paracetamol in extensive metabolisers ( and poor metabolisers $(\square)$ after single oral dose of $500 \mathrm{mg}$ phenacetin.

To qualify this difference minimum estimates of the apparent firstorder rate constants for the formation of paracetamol $\left(\mathbf{K}_{\mathbf{F} \text { paracetamol }}\right)$ were calculated from the urinary data (table II). ${ }^{1314}$ The mean value of the rate constant for the PM phenotype was $0.09 \pm$ SD 0.024 , and for the EM phenotype $0 \cdot 277 \pm 0 \cdot 064$. This difference was significant $(\mathbf{P}<0.005)$. Thus the rate of oxidative de-ethylation of phenacetin in the EM subjects was about three times faster than in the PM subjects.

\section{Discussion}

We have shown that the genetically determined hydroxylation polymorphism described for debrisoquine also controls the oxidative metabolism of guanoxan and phenacetin. Thus the same genetic defect appears to influence metabolic oxidative processes at such dissimilar carbon centres as the aromatic 6- and 7-carbon centres of guanoxan, the alicyclic 4-carbon centre of debrisoquine, and the aliphatic $x$-carbon centre of phenacetin. Hence the defect apparently influences some component common to the processes concerned in the oxidation of several dissimilar centres. Whether the defect influences oxidation at non-carbon functions in drugs, such as nitrogen and
TABLE II-De-ethylation of phenacetin and hydroxylation phenotypes of eight volunteers

\begin{tabular}{|c|c|c|c|c|c|c|c|c|c|}
\hline Subject & & 1 & 2 & 3 & 4 & 5 & 6 & 7 & 8 \\
\hline $\begin{array}{l}\text { Hydroxylation phenotype } \\
\text { KF paracetamol/hour* }^{*}\end{array}$ & $\ldots$ & $\begin{array}{l}\text { PM } \\
0.07\end{array}$ & $\begin{array}{l}\text { PM } \\
0.09\end{array}$ & $\begin{array}{l}\text { PM } \\
0.13\end{array}$ & $\begin{array}{l}\text { PM } \\
0.09\end{array}$ & $\begin{array}{l}\text { EM } \\
0.36\end{array}$ & $\begin{array}{l}\text { EM } \\
0.25\end{array}$ & $\begin{array}{l}\mathrm{EM} \\
0 \cdot 21\end{array}$ & $\begin{array}{l}\text { EM } \\
0 \cdot 30\end{array}$ \\
\hline
\end{tabular}

*First-order rate constant for formation of paracetamol-see tex PM = Poor metabolisers. EM= Extensive metabolisers.

sulphur centres, is unknown and is under investigation, but it certainly seems plausible.

The main implication of our findings is that the metabolism of a whole range of drugs that are metabolised by oxidation at carbon centres may be defective in some people. The question therefore arises of the possible consequences of this. The first point to consider is the size of the group. Our studies with debrisoquine metabolism suggest that among Caucasians the prevalence of the defect is about $5 \%$. Thus a town with a population of about 200000 would be expected to include about 10000 people defective in their capacity to metabolise drugs. Furthermore, a GP with a list of, say, 3000 might expect to have around 150 defective hydroxylators. Clearly the prevalence of the defect is too high to be ignored. The second question is whether the defect alters people's responsiveness to drugs. Little information on this is available at present, but existing data suggest that it does. We, for example, showed that people with an oxidation defect for debrisoquine are much more sensitive to the hypotensive effects of this drug than are extensive metabolisers. ${ }^{8}$ Some of the poor metabolisers reported severe side effects when given therapeutic doses of the drug. Shahidi studied the pedigree of two sisters with a faulty de-ethylation of phenacetin similar to that described by us and found that they were exceptionally sensitive to the methaemoglobin-producing effects of the drug. ${ }^{15}$ In our view many of the side effects reported for drugs will be found to have their origins in a genetically determined impaired ability to oxidise drugs.

The third point to consider is the practical implications of these findings in the development of new drugs and the use of drugs. So far as metabolic studies on man are concerned contemporary practice is singularly ineffective in detecting interindividual variations in drug metabolism. This is because the number of subjects studied is usually small (three to six) and therefore rarely permits the detection of pronounced intersubject variations. Also, current practice in using pharmacokinetic analyses of drug disposition may disguise important aspects of intersubject variation in handling drugs. This is because of the common use of hybrid pharmacokinetic variables-for example, plasma elimination $t \frac{1}{2}$, whole-body clearance rates, etcwithout defining their major components-for example, metabolism-which may show pronounced interindividual variation without this necessarily being clearly evident when subjects are evaluated in terms of hybrid variables. This is exemplified in the case of debrisoquine itself. The first-order rate constant for the overall elimination of debrisoquine $(K)$ did not differ significantly between the extensive and poor metabolising phenotypes-EM $(n=4): K=0 \cdot 20 \pm 0.04 / h ; P M$ $(n=4): K=0 \cdot 16 \pm 0 \cdot 13 / h$-whereas the respective rates of formation of the pharmacologically inactive 4-hydroxy metabolite $\left(\mathrm{K}_{\mathrm{F}}\right)$ did differ significantly-EM: $\mathrm{K}_{\mathrm{F}}=0.05 \pm 0.02 / \mathrm{h} ; \mathrm{PM}$ $\mathrm{K}_{\mathrm{F}}=0.0015 \pm 0.0007 / \mathrm{h} ; \mathrm{P}<0.025$.

In our view the present practice for the metabolic evaluation of new drugs needs to be revised. It is important to define the metabolic variability that may be encountered for a particular drug and to evaluate its implications in terms of drug use and possible side effects. The problems of such an approach are not insuperable. We advocate that information of this sort would be best obtained by studying drug disposition and effects in panels of subjects previously phenotyped for oxidation status. Techniques for ascertaining this have been described.?

TPS is in receipt of an MRC studentship. AM is grateful to the 
EAR Educational Bureau for a scholarship. We thank the Wellcome Trust for a grant for interdisciplinary research, and Pfizer Ltd for the samples of guanoxan and metabolites.

\section{References}

${ }^{1}$ Drayer, D E, and Reidenberg, M M, Clinical Pharmacology and Therapeutics, 1977, 22, 251.

${ }^{2}$ Lunde, P K M, Frislid, K, and Hansteen, V, Clinical Pharmacokinetics, $1977,2,182$

3 Price Evans, D A, in Drug Metabolism from Microbe to Man, ed D V Parke and R L Smith, p 369. London, Taylor Francis, 1977.

4 Kalow, W, Annals of the New York Academy of Sciences, 1971, 179, 654.
5 Vessell, E S, Federation Proceedings, 1972, 31, 1253

6 Whittaker, J A, and Evans, D A P, British Medical fournal, 1970, 4, 323.

'Mahgoub, A, et al, Lancet, 1977, 2, 584.

${ }^{8}$ Idle, J R, et al, Life Sciences, 1978, 22, 979.

9 Jack, D B, Stenlake, J B, and Templeton, R, Xenobiotica, 1972, 2, 35.

10 Erdtmansky, P, and Goehl, T J, Analytical Chemistry, 1975, 47, 750.

11 Brodie, B B, and Axelrod, J, fournal of Pharmacology and Experimental Therapeutics, 1948, 94, 29.

12 Chafetz, L, et al, fournal of Pharmaceutical Sciences, 1971, 60, 463.

13 Martin, B K, Nature, 1967, 214, 247.

14 Cummings, A J, King, M L, and Martin, B K, British fournal of Pharmacology and Chemotherapy, 1967, 29, 150.

15 Shahidi, N T, Annals of the New York Academy of Sciences, 1968, 151, 822.

(Accepted 5 fuly 1978)

\title{
Beclomethasone dipropionate dry-powder inhalation compared with conventional aerosol in chronic asthma
}

\author{
J CARMICHAEL， D DUNCAN， G K CROMPTON
}

British Medical fournal, 1978, 2, 657-658

\section{Summary and conclusions}

In a double-blind study beclomethasone dipropionate inhaled as a dry powder in doses of $100 \mu \mathrm{g}$ four times daily and $150 \mu \mathrm{g}$ four times daily was compared with the conventional aerosol dose of $100 \mu \mathrm{g}$ four times daily in 20 outpatients with chronic asthma. Each of the three treatments was given for four weeks. The dry powder in a dose of $150 \mu \mathrm{g}$ four times daily had advantages over the other two treatments in terms of $F_{12}$ and the number of exacerbations of asthma during the study. There were no adverse reactions to inhaling dry-powder beclomethasone.

It was concluded that this new way of administering the drug was effective in chronic asthma, and should allow most patients with chronic asthma who cannot use conventional pressurised aerosols efficiently to benefit from inhaled corticosteroid treatment.

\section{Introduction}

Many patients with chronic asthma have benefited from corticosteroid treatment by inhalation, since in this form the drugs are locally active and free from systemic side effects. Nevertheless, only patients who can use pressurised aerosols efficiently have been able to benefit from this route of administration. Many adult patients cannot use conventional pressurised inhalers correctly even after careful tuition, ${ }^{1}$ and unfortunately, a high proportion are elderly patients in whom the side effects of systemic corticosteroid treatment, notably osteoporosis, are often more troublesome than in younger patients. Generally, young children have been denied the advantages of inhaled

Respiratory Unit, Northern General Hospital, Edinburgh EH5 2DQ, and Department of Respiratory Diseases, University of Edinburgh J CARMICHAEL, MB, CHB, registrar

D DUNCAN, MB, CHB, research assistant

G K CROMPTON, MB, FRCPED, consultant physician corticosteroids, since few can be taught to inhale fluorocarbonpropelled drug aerosols properly. Most adults and many young children can use dry-powder inhalers, however, and beclomethasone dry powder for inhalation may therefore allow most asthmatic patients to benefit from inhaled corticosteroid treatment.

We designed a comparative study of the efficacy of beclomethasone dipropionate inhaled as a dry powder and as a conventional pressurised aerosol suspension.

\section{Patients and methods}

Twenty adult outpatients with chronic asthma (11 men, 9 women; age range 30-65) who were receiving treatment with beclomethasone aerosol were selected. Each patient used a salbutamol aerosol on most days of the week to control mild symptoms, but none was receiving systemic corticosteroids. Before entry it was confirmed that the patients could use a conventional pressurised aerosol and the dry-powder inhaler (Rotahaler) efficiently. The study was a doubleblind comparison of the following treatments, all patients receiving each treatment in random order for four-week periods: (1) placebo aerosol plus $100 \mu \mathrm{g}$ beclomethasone dry powder four times daily; (2) placebo aerosol plus $150 \mathrm{\mu g}$ beclomethasone dry powder four times daily; (3) $100 \mu \mathrm{g}$ beclomethasone aerosol plus placebo dry powder four times daily. The dry-powder beclomethasone was inhaled from a capsule via a Rotahaler. The patients were asked to inhale one dose from the pressurised aerosol, then the contents of the capsule followed by a second dose from the aerosol on every occasion.

After the double-blind period of the study four weeks of placebo aerosol and placebo dry-powder treatment was given to all patients who had completed the active treatment months without developing an exacerbation of asthma severe enough to warrant treatment with prednisolone by mouth. Patients with exacerbations received prednisolone $20 \mathrm{mg}$ /day for one week and subsequently active beclomethasone aerosol, and were temporarily withdrawn from the trial for four weeks. They were then re-entered in the next active treatment group. If deterioration occurred during the final four-week single-blind doubleplacebo section the patient was immediately withdrawn and appropriate treatment given.

All patients completed diary cards and assessed their overall asthma symptoms for each day and night by marking a $50-\mathrm{mm}$ line marked "no symptoms" at one end and "severe symptoms" at the other. Also graded by the patients at the same times and by the same method were symptoms of breathlessness, wheeze, and cough. Peak expiratory flow rate (PEFR) was measured with a Wright's peak-flow meter and 